\title{
Dijital Teknolojilere Erişim Motivasyonu Ölçeğinin Türkçe'ye Uyarlanması: Geçerlik ve Güvenirlik Çalışması
}

\section{Adaptation of Motivational Access to Digital Technologies into Turkish: The Study of Validity and Reliability}

\author{
Şefika Şule ERÇETiN*
}

Öz. Bu araştırmanın amacı, Soomro, Kale, Curtis, Akcaoglu ve Bernstein (2018) tarafınca geliştirilen Öğretim Üyelerinin Bilgi ve İletişim Teknolojilerine Erişim Ölçeği'nin bir alt boyutunu, Dijital Teknolojilere Erişim Motivasyon Ölçeği olarak Türkçe'ye uyarlamaktır. Illk olarak, ölçeğin Türkçe sürümünün dilsel eşdeğerliğinin sağlanmıştır. Sonrasında, ölçeğin yapı geçerliliğini test etmek amacıyla Açımlayıcı Faktör Analizi (AFA) için 250 ve son olarak Doğrulayıcı Faktör Analizi (DFA) için gönüllük esasına dayalı olarak 200 öğretmenden veri toplanmıştır. AFA sonucuna göre; Ingilizce sürümünde olduğu gibi ölçeğin Türkçe sürümü iki alt faktörden oluşmuştur. iç̧sel motivasyon ve dişsal motivasyon alt faktörlerinin her biri 4 madde olmak üzere toplamda ölçek 8 maddeden oluşmuştur. AFA sonrasında gerçekleştirilen DFA sonucu, faktör yapısının kabul edilebilir olduğunu göstermiştir. Cronbach Alpha katsayısı ölçeğin tamamı için .51; içsel motivasyon alt faktörü için .60 ve dışsal motivasyon alt faktörü için .71 bulunmuştur. Sonuç olarak, uyarlanan ölçeğin Türk Kültüründe içsel ve dişsal dijital teknolojilere yönelik erişim motivasyonunun belirlenmesinde kullanılabileceği, ölçeğin psikometrik özelliklerinin iyileştirilmesine yönelik çalışmalar yapılmasına devam edileceği söylenebilir.

Anahtar Kelimeler: Dijital bölünme, dijital teknolojiler, motivasyon, eğitim, geçerlik, güvenirlik.

\begin{abstract}
The aim of this study is to adapt 'Motivational Access' sub-dimension of Faculty's Information and Communication Technology Access (FICTA) (Soomro, Kale, Curtis, Akcaoglu ve Bernstein, 2018) into Turkish. Firstly, English and Turkish forms were administered to 40 teachers who are expert in English. The Pearson Correlation Coefficient which ranged from $.87-.95$ which indicates that Turkish version of the scale has language validity. Later, to examine construct validity of the scale, data were collected from 250 volunteer teachers for the Exploratory Factor Analysis (EFA) and from 200 volunteer teachers for the Confirmatory Factor Analysis (CFA) respectively. According to the results of the EFA, as in English version, Turkish version of the scale consisted of two sub-scales. The endogenous motivational access and the exogenous motivational access subscales had both 4 items. After EFA, CFA was accomplished with different data sets and the factor structure was determined to be acceptable. Reliability of the scale was determined through Cronbach's Alpha Coefficient which was .51 for the overall of the scale. It was .60 for the endogenous motivational access subscale and .71 for the exogenous motivational access subscale. In conclusion, the adapted scale is a valid, reliable and measurement tool for Turkish culture.
\end{abstract}

\section{Toplumsal Mesaj.}

'Dijital bölünme dijital teknolojilere erişim motivasyonu' bireyin genel olarak bilgi ve iletişim teknolojilerini özellikle de bilgisayar ve Internet'i kullanmaya karşı içten ve dış kaynaklardan gelen isteklendirme durumları olarak tanımlanabilir. Bu çalışmada Dijital Teknolojilere Erişim Motivasyon Ölçeği Türkçe'ye uyarlanmıştır. Çalışmadaki bulgulara göre; ölçeğin dil ve yapı geçerlik ve güvenirliğinin kabul edilebilir değerler arasındadır.

\section{Public Interest Statement.}

'Digital divide motivational access to digital technologies' can be defined as motivations of an individual from inside and outside, for use of ICT. The aim of this research is to adapt Digital Divide Motivational Access to Digital Technologies into Turkish language. The findings proved that the final Turkish version of the scale was valid and reliable.

Keywords: Digital divide, digital technologies, motivation, education, validity, reliability.

\footnotetext{
* Orcid ID: http://orcid.org/0000-0002-7686-4863, Prof. Dr., Hacettepe Üniversitesi, Eğitim Fakültesi, Eğitim Bilimleri Bölümü, sefikasule@gmail.com

** Orcid ID: http://orcid.org/0000-0001-9406-8011, Doç. Dr., Hacettepe Üniversitesi, Eğitim Fakültesi, Eğitim Bilimleri Bölümü, satbasli@gmail.com

*** Orcid ID: http://orcid.org/0000-0002-1318-9362, PhD., Hacettepe Üniversitesi Eğitim Bilimleri Enstitüsü, Eğitim Bilimleri-Eğitim Yönetimi Bilim Dalı, durnali@gmail.com
} 


\section{GiRiş}

Günümüzde; sürekli olarak yeni bilgilerin üretimi gerçekleşmekte, bilgiyi yaymaya ilişkin araçlar aralıksız denebilecek biçimde yeni formlar ile yenilenmekte ve bu temelde bilgi tüketimi yoğun biçimde gerçekleşmektedir. Süregelen araştırmalar, icatlar ve keşifler, sanat eserleri aracılı̆̆ıyla yeni bilgilerin çeşitli disiplinlerde birikmesine bilim ve sanat aracı olmaktadırlar... Bu bilgiler hem bireysel ve hem de örgüt faaliyetlerinde, bu faaliyetleri kolaylaştırıcı etkisi önemli olan yeni veya güncel teknolojiler olarak somutlaşabilmektedir (Akbaşlı ve Durnalı, 2017:728). Böyle bir dünyada, insanların işlerini ve yaşam tarzlarını geliştirmek amacıyla yeni teknolojileri kullananlarla rekabet edebilmek için teknoloji destekli uygulamalara katılmaları gerekmektedir. Ne yazık ki, herkes bilgi ve iletişim teknolojilerine eşit erişime sahip değildir. Bunun bir sonucu ise, bilgi ve iletişim teknolojileri erişimleri sınırlı olan insanların erişimi sınırlı olmayanlara göre etkili bir şekilde topluma katılmamalarıdır (Soomro, Kale, Curtis, Akcaoglu ve Bernstein, 2018). Bu teknolojilerin bireylerce, gruplarca, örgütlerce kullanımında farklııklar olabileceği gerçeğinin beraberinde dijital bölünme kavramını doğurduğu açıktır. Şöyle ki, Ege (2008)'ye göre yeniliklerin en hızlı yaşandığı bir alan olan bilgi iletişim teknoloji sayesinde bilginin yönlendirilmesi hızlı, kolay ve ucuz olarak gerçekleştirilebilmektedir. Ancak, Akyazı (2007)'ya göre toplumların bu teknolojilere erişme hızı bu teknolojilerin yenilenme hızına eşit değildir.

Illk olarak 1980'li yılların ortasına doğru Amerika Birleşik Devletleri kültüründe bilgi ve iletişim teknolojilerine sahiplik bağlamında yaşanan eşitsizliklere dikkat çekmek için kullanılmaya başlanılan (Özcivelek, Aşkar, Geray, Tüfekçi, Zontul ve Küçükçınar, 2000), Türkçe'de “Sayısal uçurum, sayısal bölünme, sayısal eşitsizlik ve erişim uçurum" (Oruç ve Arslan, 2002) kavramları ile de ifade edilen "dijital bölünme", fiziksel erişim sorunlarının ötesine uzanan, karmaşık ve çok boyutlu bir olgudur (Soomro, Kale, Curtis, Akcaoglu, ve Bernstein, 2018). Bu çalışmada bu olguyu ifade etmek için "Dijital bölünme" sözcükleri kullanılmıştır. "Dijital bölünme" terimi genelde farklı uluslar ya da sosyo-ekonomik grupların teknolojiye erişimlerindeki farklılık (Norris, 2001), teknolojiyi etkili biçimde kullanmak için gerekli olan sosyal ve örgütsel kaynaklara erişimdeki farklılık (Warschauer, 2004), bireylerin teknolojiye erişmelerindeki farklılıklar (Atkinson, Black ve Curtis, 2008), yaşa bağlı olarak teknoloji kullanım becerilerinde bireylerdeki farklılıklar -bilgisayar ve İnternet'e doğan yeni nesil 'dijital yerli' ve belirli bir yaştan sonra bilgisayar ve İnternet'i kullananlar bireyler ise 'dijital göçmen'- (Prensky, 2001) olarak tanımlanmaktadır. Diğer bir tanımla, farklı coğrafi ve sosyo-ekonomik bölgelerde faaliyet gösteren örgütlerin ve bireylerin, bilgi ve iletişim teknolojilerine erişim imkânlarındaki adaletsizlik, dijital bölünme olarak tanımlanmaktadır (Oruç ve Arslan, 2002). Bu olgu, bir toplum içerisinde farklı gruplar arasında görülebileceği gibi farklı ülkeler arasında da görülebilir (Seferoğlu, Avcı ve Kalaycı, 2008). Gelir, ırk, cinsiyet, konum veya eğitim gibi kategorilere dayalı teknoloji deneyimine erişim ve eşitlikte önemli bir fark anlamına gelir (Swain ve Pearson, 2001). Benzer bir tanımda cinsiyet, eğitim durumu, aylık gelir, yaşanılan coğrafi alan özellikle ekonomik farklııkların çok belirgin olduğu yerler - gibi çeşitli değişkenlere göre bireylerin, bilgi ve iletişim teknolojilerine erişimdeki eşitsizliği ifade etmektedir (Ilgaz ve Seferoğlu, 2010). Kurumsal temelli diğer bir tanımlama çabasında ise "dijital uçurum" terimi, hem bilgi ve iletişim teknolojilerine (Віт) hem de İnterneti çok çeşitli aktiviteler için kullanma ve erişim fırsatlarına (imkânlarına) göre farklı sosyo-ekonomik düzeylerden bireyler, hane halkları, işletmeler ve coğrafi bölgeler arasındaki uçurumu ifade eder. Dijital uçurum, ülkeler içinde ve ülkeler arasında çeşitli farklılıkları yansıtır (OECD, 2001). Farklı bilgi ve teknik beceriler nedeniyle bilgi ve iletişim teknolojilerinin etkili bir şekilde kullanabilmeleri açısından gruplar arasındaki farklılıkları ifade eder (Tien ve Fu, 2008). Bu tanımlamalarda öne çıkan nokta dijital teknolojilere erişimdeki farklılıklardır. Ayrıca, bilgi ve teknik becerilerdeki farklılıklara da vurgu yapılmıştır. Bu farklııklar kadar bu teknolojileri benimseme motivasyonu da önemlidir.

Dijital bölünme, eğitim örgütlerinde de görülmektedir (Aksoy, 2003). Ancak, eğitim alanında yürütülen mevcut dijital bölünme araştırmalarının büyük ölçüde öğrencilerin okullarda ve evlerde bilgi ve iletişim teknolojilerine fiziksel erişimine odaklandığı sınırlı yollarla ele alınmıştır (Ritzhaupt, 
Liu, Dawson ve Barron, 2013). Dijital teknolojilere sahip olanlarla olmayanlar (ya da güncel teknoloji kullananlar ile kullanmayan eğitim örgütleri çalışanları ve öğrenciler arasında), dijital teknolojilere karşı motivasyonu olanlarla olmayanlar arasında farklılık olabilmektedir. Bu çalışma ise yeni dijital bölünme teorisinin (Bilgi ve iletişim teknolojilerine fiziksel erişim dışındaki yönleri de dikkate alan) (Soomro, Kale, Curtis, Akcaoglu ve Bernstein, 2018) odağında yer alan “Dijital Teknolojilere Erişim Motivasyon" konusuna yoğunlaşmıştır.

Erişim motivasyonu, bir kişinin dijital teknolojileri benimseme, edinme, öğrenme ve kullanma isteğini ifade eder (Van Dijk, 2005). Erişim içsel motivasyonu, bireyin içinden kaynaklanan ve dış kaynaklardan doğrudan etkilenmeyen bilgi ve iletişim teknolojilerini (BIT) benimseme isteğini ifade eder. Öte taraftan, dışsal erişim motivasyonu, bireyin sosyal etki, zaman ve maddi kaynaklar dâhil olmak üzere dış kaynaklardan kaynaklanan BiT'i benimseme isteğini gösterir (Soomro, Kale, Curtis, Akcaoglu ve Bernstein, 2018).

Hızlı değişimlerin gerçekleştiği bilgi çağında gerek bilginin kapsamı gerekse teknolojik ilerlemeler hızla değişmekte ve yayılmaktadır. Eğitim sistemleri de bu hızlı değişimlere ayak uydurma uğraşısındadır. Bu temelde, dijital bölünme tüm dünyada endişe ile karşılanmakta ve bu konuda çözümler üretme noktasında çeşitli faaliyetler gerçekleştirilmektedir. Bu noktada, doğru çözümler üretebilmek için öncelikle mevcut durumun belirlenmesi önemlidir (Seferoğlu, Avcı ve Kalaycı, 2008). Bu bağlamda öğretmenlerin dijital teknolojilere erişim motivasyonuna yönelik tutum ve inançlarının belirlenmesi oldukça önemlidir. Bu uyarlama çalışması, “Dijital Teknolojilere Erişim Motivasyon Ölçeği" ile öğretmenlerin içinden (içsel) ve dışından (dışsal) gelen istek temelinde dijital teknolojilere erişime yönelik kendileriyle ilgili algılarını ölçme uğraşısındadır. Türk Kültürü’ne uyarlanan geçerlilik ve güvenilirliği kabul edilebilir sınırlar içinde olan bu ölçek, dijital bölünme konusunun dijital teknolojilere yönelik erişim motivasyonu değişkenin ölçülmesi açısından literatüre katkı sağlayacaktır.

\section{YÖNTEM}

Bu çalışma, bir ölçeğin bazı faktörlerinin Türkçe'ye uyarlandığı bir ölçek geliştirme çalışmasıdır. Çalışma kapsamında önce dilsel eşdeğerlik incelenmiş, bunun ardından Açımlayıcı Faktör Analizi ve Doğrulayıcı Faktör Analizi gerçekleştirilmiştir. Bu çalışmalarda yer alan katılımcıların özellikleri çalışma grubu başlı̆̆ altında verilmiştir.

\section{1 Çalışma Grubu}

Bu çalışma üç farklı çalışma grubu üzerinde gerçekleştirilmiştir. Öncelikle ölçeğin dilsel eşdeğerliğini test etmek için, İngilizce bilgisi iyi sevide olan İngilizce öğretmenleri çoğunluk olmak üzere toplamda 40 öğretmene ölçeğin İngilizce ve Türkçe formları 15 gün arayla uygulanmıştır. Sürecin bir sonraki adımında, ölçeğin Türkçe formları Açımlayıcı Faktör Analizi (AFA) için toplamda gönüllük esasına dayalı olarak 250 öğretmene uygulanmıştır. Bu çalışma grubunun büyüklüğünün uygunluğunun dayanağında şu bilgi yer almaktadır. 100 kişiden az olmamak kaydıyla, çalışma grubunun faktör analizi uygulanacak ölçek madde sayısının en az 5 katı büyüklükte olması gerekmektedir (Bryman ve Cramer, 1999; Tavşancıl,2002). Bu ikinci çalışma grubunu oluşturan öğretmenlerin demografik bilgileri Tablo 1'de sunulmuştur. 
Tablo 1. AFA çalışma grubuna ait demografik bilgiler

\begin{tabular}{lllll}
\hline Değişkenler & Grup & N & $\%$ & Toplam \\
\hline Cinsiyet & Kadın & 151 & 60,4 & 250 \\
& Erkek & 99 & 39,6 & \\
Yaş & $20-30$ & 42 & 16,8 & 250 \\
& $31-40$ & 138 & 55,2 & \\
& $41-50$ & 43 & 17,2 & \\
& 51 ve üzeri & 27 & 10,8 & \\
& $0-5$ yıl & 40 & 16 & 250 \\
Mesleki kıdem & $6-10$ yıl & 56 & 22,4 & \\
& $11-15$ yıl & 74 & 29,6 & \\
& $16-20$ yıl & 40 & 16,0 & \\
& 21 yıl ve üzeri & 40 & 16,0 & \\
Öğrenim Durumu & Lisans & 117 & 46,8 & 250 \\
& Yüksek Lisans & 110 & 44,0 & \\
\hline & Doktora & 23 & 9,2 & \\
\hline
\end{tabular}

Cinsiyet açısından çalışma grubunun \%60,4 kadın öğretmenlerden ( $f=151), \% 39,6^{\prime}$ ise erkek öğretmenlerden ( $f=99$ ) oluşmaktadır. Yaş açısından öğretmenlerin yarıdan fazlası $(f=138), \% 55,2^{\prime} i$ 31-40 yaş aralığındadır. Mesleki kıdem açısından ise alt gruplar arasında birbirine yakın bir dağılım söz konusudur denilebilir. Öğrenim durumu değişkeni açısından ise $(f=23), \% 99,2^{\prime} i$ doktora diplomasına sahiptir. Sürecin son adımında, ölçeğin Türkçe formları Doğrulayıcı Faktör Analizi (DFA) için toplamda gönüllük esasına dayalı olarak 200 öğretmene uygulanmıştır. Bu üçüncü çalışma grubunu oluşturan öğretmenlerin demografik bilgileri Tablo 2'de sunulmuştur.

Tablo 2. DFA çalışma grubuna ait demografik bilgiler

\begin{tabular}{llccc}
\hline Değişkenler & Grup & $N$ & $\%$ & Toplam \\
\hline Cinsiyet & Kız & 127 & 63,5 & \multirow{2}{*}{200} \\
& Erkek & 73 & 36,5 & \\
\hline Yaş & $20-30$ & 36 & 18,0 & \\
& $31-40$ & 110 & 55,0 & 200 \\
& $41-50$ & 32 & 16,0 & \\
& 51 ve üzeri & 22 & 11,0 & \\
\hline \multirow{3}{*}{ Mesleki kıdem } & $0-5$ yıl & 34 & 17,0 & \\
& $6-10$ yıl & 47 & 23,5 & \\
& $11-15$ yıl & 57 & 28,5 & 200 \\
& $16-20$ yıl & 30 & 15,0 & \\
Öğrenim Durumu & 21 yıl ve üzeri & 32 & 16,0 & \\
& Lisans & 98 & 49,0 & \\
& Yüksek Lisans & 85 & 42,5 & 200 \\
& Doktora & 17 & 8,5 &
\end{tabular}

Cinsiyet açısından DFA çalışma grubunun \%63,5'i kadın öğretmenlerden ( $f=127), \% 36,5$ ise erkek öğretmenlerden ( $f=73$ ) oluşmaktadır. Yaş açısından öğretmenlerin yarıdan fazlası ( $f=110), \% 55^{\prime} i$ 3140 yaş aralığındadır. Bu oran bu araştırmanın AFA çalışma grubu yaş değişkeni oranı ile benzerlik 
taşımaktadır. Mesleki kıdem değişkeni açısından ise 11-15 yıl grubu ( $f=57), \% 28,5$ oranı ile en büyük paya sahiptir. Öğrenim durumu değişkeni açısından ise çalışma grubunu oluşturan öğretmenlerin yarıya yakını ( $f=98), \% 49,0$ ' lisans diplomasına sahiptir.

\section{2 Ölçme Aracı}

Bu çalışmada uyarlama çalışmasında temel alınan ölçek; Soomro, Kale, Curtis, Akcaoglu ve Bernstein (2018) tarafından geliştirilen Dijital Bölünme: Öğretim Üyelerinin Bilgi ve İletişim Teknolojilerine Erişimi Ölçeğidir. Bu çalışmada, bu ölçeğin bir alt boyutu olan Dijital Teknolojilere Erişim Motivasyon Ölçeği (DTEM-Ö)'nin Türk Kültürüne uyarlaması gerçekleştirilmiştir. Bu uyarlanan boyutun bağımsız bir ölçme potansiyeli taşıdığı tespitinden hareketle; bu boyutun bağımsız bir ölçme aracı olarak uyarlanması noktasında ölçeği geliştiren sorumlu araştırmacıdan eposta aracılığıyla izin alınmıştır. Bu ölçek, her bir boyutta dörder madde olmak üzere iki alt boyut ve toplamda sekiz maddeden oluşmaktadır. Ölçeğin ilk alt boyutunu "içsel Motivasyon" (Endogenous Motivational Access) ve ikinci alt boyutunu "Dişsal Motivasyon" (Exogenous Motivational Access) oluşturmaktadır. Ölçeğin özgün dili İngilizce'dir ve öğretim üyeleri için geliştirilmiştir. Orijinal çalışmada ölçeğin güvenirlik katsayıları ise şu şekildedir:

Tablo 3. Özgün Ölçeğin Cronbach's Alpha Güvenirlik Katsayıları

\begin{tabular}{lc}
\hline Alt Boyutlar & Cronbach's Alpha \\
\hline Endogenous Motivational Access (İçsel Motivasyon) & 0,81 \\
Exogenous Motivational Access (Dışsal Motivasyon) & 0,88
\end{tabular}

Ölçek, "Kesinlikle Katılmıyorum (1)" , "Katılmıyorum (2)" , "Kararsızım (3)" , "Katılıyorum (4)" , "Kesinlikle Katılıyorum (5)" olmak üzere 5'li Likert tipindedir ve ikinici madde ters puanlanan bir maddedir. Bir boyuta ilişkin puan hesaplanmasında, her bir boyutta yer alan dört maddenin ortalama puanı hesaplanmalıdır. Ölçek geneli puan hesaplanmasında ise sekiz maddenin ortalama puanı hesaplanmalıdır. DTEM-Ö puanlarının aritmetik ortalamasının derecelendirme düzeylerine Tablo 4'de yer verilmiştir. Çalışmalarda aritmetik ortalama değerleri yorumlanırken bu katılım düzeyi aralıkları dikkate alınmalıdır.

Tablo 4. DTEM-Ö Seçeneklerine Karşılık Gelen Puan Aralıkları

\begin{tabular}{llc}
\hline Derece & Seçenekler & Puan Aralıkları \\
\hline 1 & Kesinlikle Katılmıyorum & $1,00-1,80$ \\
2 & Katılmıyorum & $1,81-2,60$ \\
3 & Kararsızım & $2,61-3,40$ \\
4 & Katılıyorum & $3,41-4,20$ \\
5 & Kesinlikle Katılıyorum & $4,21-5,00$ \\
\hline
\end{tabular}

\subsection{Verilerin Analizi}

Bu çalışmada uyarlanan "Dijital Teknolojilere Erişim Motivasyon Ölçeği" için öncelikle, dil geçerliği kapsamında korelasyon analizi gerçekleştirilmiştir. Bu uyarlanan ölçek, aslında "Öğretim Üyelerinin Bilgi ve Illetişim Teknolojilerine Erişimi Ölçeği'nin" bir alt boyutu olduğu ve ayrıca özgün ölçeğin geçerlik ve güvenirliği öğretim üyeleri üzerinde gerçekleştirildiğinden dolayı bu uyarlama çalışmasının ise öğretmenler üzerinde yürütüldüğü için yapı geçerliği çalışması kapsamında öncelikle AFA gerçekleştirilmiştir. AFA'da faktör analizi için temel bileşenler analizi ile Varimax dik döndürme tekniği kullanılarak varyans oranı, KMO değeri ve Bartlett testi, faktör yük değerleri ve madde toplam korelasyon hesaplanmıştır ve öz değer grafiği incelenmiştir. Sonrasında, AFA sonucunda elde edilen model DFA ile test edilmiştir. DFA'da faktör yük değerleri, maddeler ve boyutlar arasındaki yol katsayıları, $t$ testi değerleri ve uyum iyiliği değerleri hesaplanmıştır. Güvenirlik çalışmasında ise iç tutarlılık katsayısı için Cronbach Alpha güvenirlik katsayısı ve Korelasyon katsayısı hesaplanmıştır. Verilerin analizinde LiSREL 8.7 ve SPSS 20 i̇statistik Programlarından yararlanılmıştır. 


\section{BULGULAR}

Bu bölümde DTEM-Ö'nin geçerlik ve güvenirlik analizlerine ilişkin bulgulara yer verilmektedir. Bulgular tablolar halinde sunulmakta ve tablolara ilişkin yorumlar yapılmaktadır.

\subsection{Dil Geçerliği}

Illk önce, İngilizce bilgisi üst düzeyde olan üç alan uzmanınca orta noktada buluşularak ölçek maddeleri Türkçe'ye çevrilmiştir. Çeviri, maddelerin ifade edilişi ve dilbilgisi kuralları temelinde doğruluğu noktasında üç Türk Dili uzmanına kontrol ettirilmiştir. Çevrilen ölçeğin dil geçerliğini test etmek için ölçeğin önce İngilizce sürümünü 40 İngilizce öğretmeni cevaplamış, aynı öğretmen grubu 15 gün sonra ölçeğin Türkçe sürümünü cevaplanmıştır. Bu iki farklı veri seti arasındaki analize ilişkin bulgular Tablo 5'te belirtilmiştir.

Tablo 5. İngilizce ve Türkçe Formlar Arasındaki Korelasyon

\begin{tabular}{llccccc}
\hline Ölçek & Uygulama & $\mathrm{N}$ & $\overline{\mathrm{X}}$ & $\mathrm{S}$ & $\mathrm{r}$ & $p$ \\
\hline iç̧sel Motivasyon & Ingilizce Form & 40 & 3,97 & 0,54 & \multirow{2}{*}{, 87} & \multirow{2}{*}{00} \\
& Türkçe Form & 40 & 4,18 & 0,62 & & \\
\hline Dişsal Motivasyon & Ingilizce Form & 40 & 2,77 & 0,56 & \multirow{2}{*}{, 93} & \multirow{2}{*}{00} \\
& Türkçe Form & 40 & 2,77 & 0,53 & & \\
\hline Ölçek Geneli & İngilizce Form & 40 & 3,37 & 0,42 & \multirow{2}{*}{, 93} & \multirow{2}{*}{00} \\
& Türkçe Form & 40 & 3,47 & 0,43 & & \\
\hline
\end{tabular}

Tablo 5'de Dijital Teknolojilere Erişim Motivasyon Ölçeği'nin genelinde ve alt boyutlarında dil geçerliği analizi ortalama değer $(\bar{X})$, standart sapma $(S)$ ve Pearson Korelasyon katsayı ( $r$ ) değerlerine yer verilmiştir. Buna göre, ilişki "içsel Motivasyon" alt boyutunda $r=0,87$ ve "Dışsal Motivasyon" alt boyutunda $r=0,93$ değerleri düzeyindedir. Ölçeğin genelinde ise $r=0,95$ düzeyinde bir ilişki saptanmıştır. Büyüköztürk (2011) 0,70-1,00 aralığında bir değerin yüksek düzeyli ilişkili olduğunu belirtmiştir. Tablo 5'de yer verilen değerlere göre, ölçeğin iki alt boyutunda ve ölçeğin genelinde İngilizce ve Türkçe analiz bulguları arasında pozitif yönlü yüksek düzeyde bir ilişki olduğu iler sürülebilir. Bu sonuç, uyarlanan ölçeğin alt boyutlarında ve genelinde dil açısından eşdeğerliğin doğrulandığını göstermektedir.

\section{2 Ölçeğin Yapı Geçerliğine İlişkin Bulgular}

\subsubsection{Açımlayıcı Faktör Analizi}

Ölçeğin yapı geçerliğini belirlemek amacıyla veriler üzerinde Açımlayıcı Faktör Analizi (AFA) uygulanmıştır. Açımlayııı faktör analizinden önce, 2. sıradaki olumsuz madde ters çevrilmiş ve sonrasında güvenirlik analizi yapılmıştır. Faktör analizi için döndürme yapmadan önce öz değeri 1.00 'den büyük iki faktör ortaya çıkmıştır. Ölçek uyarlama ile ilgili olarak faktörlerin oluşturulmasında .30 ile .45 arasında değişen faktör yüklerinin alt kesme noktası olarak alınabileceği belirtilmektedir (Büyüköztürk, 2016). Kesme noktası .30'un altı alınmış ve ölçekten madde atımı yapılmayarak sekiz madde ile analize devam edilmiştir. Faktör analizi için temel bileşenler analizi ile Varimax dik döndürme tekniği kullanılmıştır. Tablo 6'da görüldüğü gibi, iki faktörün yük dağılımlarına bakıldığında; birinci alt faktör 4 maddeden $(1,2,3,4)$ oluşmuş, öz değeri 2,69 olarak bulunmuştur. Tek başına bu alt faktör, içsel motivasyon değişkeninin \% 33,65'ünü açıklamaktadır. Ikinci alt faktör 4 maddeden $(5,6,7,8)$ oluşmuş, öz değeri 1,387 olarak bulunmuştur. Tek başına bu alt faktör ilgili dışsal motivasyon değişkenine ait varyansın \% 17,34'ini açıklamaktadır. Bu iki alt faktör birlikte ilgili motivasyon değişkenine ilişkin varyansın \% 50,99'ünü açıklamaktadır. Bu sonuç, Kline (2011) tarafından kabul edilebilir sınırlar olarak belirtilen \%41'in üzerindedir. Bu durum ölçeğin toplam varyans oranının yeterli bir değere sahip olduğunu göstermektedir. Ayrıca faktör analizinin ikinci tekrarı sonucunda KMO değeri, .72; Bartlett testinin anlamlılık düzeyi ise 0.000 olarak bulunmuştur $(\chi 2=378.558$; $s d=28 ; p<.01$ ). Tablo 6 'da maddelerin açımlayıcı faktör yük dağılımları ve madde test korelasyonu değerleri yer almaktadır: 
Tablo 6. Her Değişken İçin Döndürülmüş Faktör Yükleri ve Madde Toplam Korelasyon (MTK) Değerleri

\begin{tabular}{ccccc}
\hline Madde no & Yeni no & iç motivasyon & Dış motivasyon & MTK \\
\hline 1 & 1 & .72 & & .31 \\
2 & 2 & .55 & & .32 \\
3 & 3 & .64 & & .42 \\
4 & 4 & .71 & .41 & .41 \\
5 & 5 & & .83 & .35 \\
6 & 6 & & .83 & .47 \\
7 & 7 & & .73 & .46 \\
8 & 8 & 2.692 & 1.387 & .53 \\
& Özdeğer & 33.653 & 17.341 & \\
\hline
\end{tabular}

Tablo 6 incelendiğinde, ölçeğin madde toplam korelasyonlarının .31-.53 arasında değiştiği gözlenmektedir. Korelasyon katsayısı mutlak değer olarak, .70-1.00 arasında yüksek; .70-.30 arasında orta ve .30-.00 arasında düşük düzeyde bir anlam ifade etmektedir (Büyüköztürk, 2016). Dolayısıyla, madde toplam korelasyon değerlerinin orta düzeyde olduğu görülmektedir. Ölçeğin faktör yük değerlerinin ise birinci alt boyutta $.55-.72$ arasında, ikinci alt boyutta ise $.41-.83$ arasında olduğu gözlenmektedir. Buna göre faktör yük değerlerinin orta ve yüksek düzeyde ilişkiye sahip olduğu ifade edilebilir (Büyüköztürk, 2016).

AFA sonucu elde edilen öz değer grafiği Şekil 1'de verilmiştir.

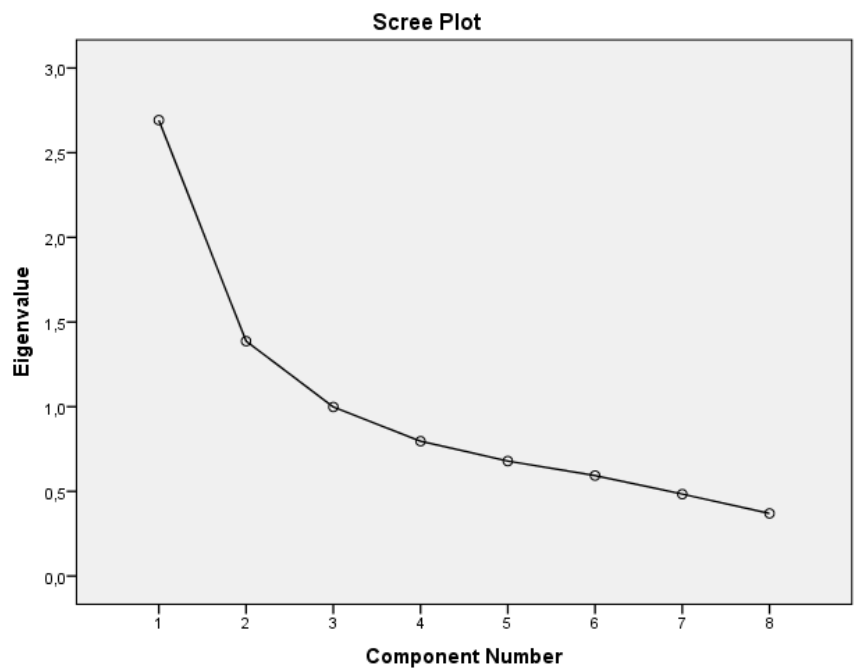

Şekil 1. AFA öz değer grafiği

Şekil 1'deki öz değer grafiği incelendiğinde, ikinci maddeden sonraki maddelerin birbirlerine yakın değerlere sahip oldukları görülmüş ve ölçek iki alt boyutlu olarak ele alınmıştır.

\subsubsection{Doğrulayıcı Faktör Analizi}

DTEM-Ö'nün AFA'dan elde edilen iki alt boyutlu yapısının test edilmesi için farklı 200 kişiden oluşan öğretmen çalışma grubuyla DFA yapılmıştır. Modelin path diagramı Şekil 2'de verilmiştir. 


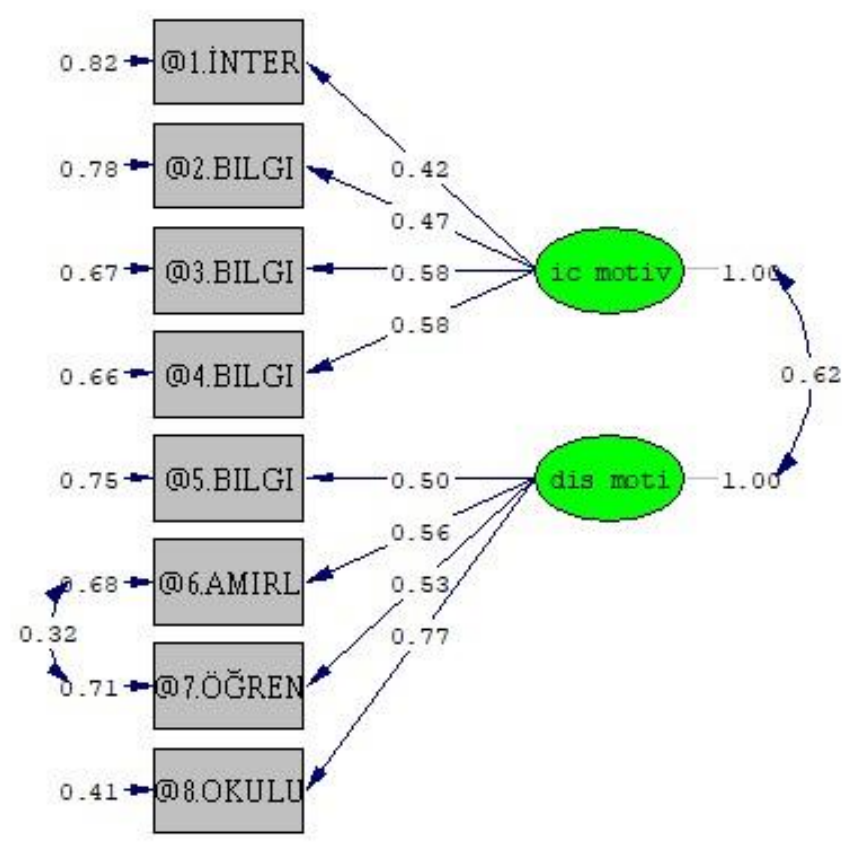

Şekil 2. Modelin Path Diagramı

Şekil 2'de, DFA için faktör yük değerlerinin .42 ile .77 arasında, hata varyans değerlerinin .41 ile .82 arasında olduğu ve tamamının anlamlı bir düzeye ulaştığı görülmektedir. Maddeler ve boyutlar arasındaki yol katsayılarının içsel motivasyon için .42-.58, dışsal motivasyon için .50-.77 arasında olduğu görülmektedir. Açıkladığı varyans ve ilişki değerleri orta ve üstü olduğu için bu değerler yeterli kabul edilir (Büyüköztürk, 2016). Şekil 2 de görüldüğü gibi; Ki kare değerini düşürmek için altıncı ve yedinci maddelerin hata varyans değerlerinde eşitleme yapılmıştır. 6. madde "Amirlerim kullanmamı beklediği için, bilgi ve iletişim teknolojilerini kullanmak istiyorum" ve 7. madde "Öğrencilerim bilgisayar ve internet'i kullanmam gerektiğini düşündüğü için bu teknolojileri kullanmak istiyorum" şeklindedir. Her iki madde de dışsal motivasyon konusunda paralel olan ifadelerdir. Bu nedenle DFA'daki hata varyanslarının eşitlenmesinin uygun bir işlem olduğu sonucuna varılabilir. DFA sonucu elde edilen iki alt boyutlu modele ilişkin t-testi değerleri Tablo 7'de sunulmuştur.

Tablo 7. DTEM-Ö için DFA'dan elde edilen $t$ testi değerleri

\begin{tabular}{cccc}
\hline Madde No & t değeri & Madde No & t değeri \\
\hline S1 & $4.96^{*}$ & S5 & $6.23^{\star}$ \\
S2 & $5.52^{\star}$ & S6 & $6.95^{\star}$ \\
S3 & $6.77^{*}$ & B7 & $6.55^{\star}$ \\
S4 & $6.86^{*}$ & B8 & $9.27^{\star}$ \\
\hline
\end{tabular}

${ }^{*} p<.01$

Tablo 7 incelediğinde, DFA analizinde t değerlerinin anlamlı bir değer aldığı görülmektedir. Kline (2011)'a göre, t-değeri için 1.96'dan büyük değerler .05 düzeyinde, 2.58'in üzerindeki değerler ise .01 düzeyinde anlamlıdır. Bu bağlamda, t-değerlerinin tamamının .01 düzeyinde anlamlı olduğu anlaşılmaktadır. 
Tablo 8. DFA Uyum İyiliği Değerleri

\begin{tabular}{lcccl}
\hline Indeks & $\begin{array}{c}\text { Normal } \\
\text { Değer }\end{array}$ & Kabul Edilebilir Değer & Elde Edilen Değer & Sonuç \\
\hline$p$ & $\mathrm{p}>.05$ & - & 0.0 & Mükemmel uyum \\
$x 2 / d f$ & $<2$ & $<5$ & 1.54 & Mükemmel uyum \\
RMSEA & $<.05$ & $<.08$ & .061 & Kabul edilebilir uyum \\
SRMR & $<.05$ & $<.08$ & .055 & Kabul edilebilir uyum \\
CFI & $>.95$ & $>.90$ & .98 & Mükemmel uyum \\
NFI & $>.95$ & $>.90$ & .93 & Kabul edilebilir uyum \\
NNFI & $>.95$ & $>.90$ & .96 & Mükemmel uyum \\
GFI & $>.95$ & $>.90$ & .97 & Mükemmel uyum \\
\hline
\end{tabular}

Kaynak: Wang ve Wang, (2012)

Tablo 8 incelendiğinde Ki-kare değeri $\chi 2(18, n=200)=27.76, p<.001$ olarak saptanmıştır. Yapılan hesaplama sonucunda $\chi 2 / s d=1.54$ değerinin kabul edilebilir düzeyde olduğu görülmüştür. RMSEA $=.061, \mathrm{SRMR}=.055, \mathrm{CFI}=.98, \mathrm{NFI}=.93, \mathrm{NNFI}=.96, \mathrm{GFI}=.97$ ile kabul edilebilir ve mükemmellik düzeyinde uyum değerlerinde olduğu saptanmıştır (Hu ve Bentler, 1999). Modelin RMSEA ve SRMR değerlerinin 0.08 'den küçük olması modelle veri uyumunun güçlü bir göstergesi olarak değerlendirilebilir (Hu ve Bentler, 1999). DFA'dan elde edilen bulgular, ölçeğin faktör yapısının kabul edilebilir uyum gösterdiğine işaret etmektedir.

\section{3. Ölçeğin Güvenirliğine iliş̧kin Bulgular}

DTEM-Ö’nün Türkçe formunun iç tutarlık katsayısının belirlenmesi için Cronbach Alpha ve Korelasyon Katsayısı hesaplanmış ve değerler Tablo 9'da verilmiştir.

Tablo 9. Alt Boyutların Ortalama (Ort), Standart Sapma (Ss), Korelasyon Katsayıları ve Cronbach Alpha Değerleri

\begin{tabular}{lcc}
\hline Alt Boyutlar & Içsel Motivasyon & Dışsal Motivasyon \\
\hline İçsel Motivasyon & 1.00 & - \\
Dışsal Motivasyon & $.35^{\star}$ & 1.00 \\
\hline Ss & 2.50 & 2.85 \\
Ort & 16.36 & 11.34 \\
Cronbach Alfa & .60 & .71 \\
Cronbach Alfa Genel & & .51 \\
\hline
\end{tabular}

${ }^{*} p<.01$

Analiz sonucunda ölçeğin iki alt boyutlu yapısına ilişkin Cronbach Alpha güvenirlik katsayısı .51 olarak bulunmuştur. Tablo 9'da görüldüğü gibi, alt boyutlara ilişkin Cronbach Alpha güvenirlik katsayısı birinci alt boyutta .60, ikinci alt boyutta .71 olarak tespit edilmiştir. Güvenirlik katsayısı için dikkate alınması önerilen ölçüt .70 olmakla birlikte (Tezbaşaran, 1997), madde sayısının 10 ve daha az olması durumunda .50 ve üzerindeki değerler kabul edilebilir olarak yorumlanmaktadır (Nunnally, 1978). Sonuç olarak, genel olarak ve alt boyutlar bağlamında değerlendirildiğinde ölçeğin hesaplanan güvenirlik katsayıları kabul edilebilir ölçütleri karşılamaktadır.

Ayrıca, içsel motivasyon ve dışsal motivasyon alt boyutlarının maddelerine ilişkin korelasyon katsayısı değerinde pozitif yönlü anlamlı doğrusal bir ilişki olduğu tespit edilmiştir $\left[r_{(250)}=.35 ; p<.01\right]$. Bu durum, içsel motivasyonu yüksek olan öğretmenlerin dışsal motivasyonun da yüksek olduğuna işaret etmektedir. 


\section{SONUÇ, TARTIŞMA VE ÖNERILER}

Bu çalışmanın amacı, Soomro, Kale, Curtis, Akcaoglu ve Bernstein (2018) tarafından geliştirilen Öğretim Üyelerinin Bilgi ve İletişim Teknolojilerine Erişimi Ölçeği'nin bir alt boyutu olan Dijital Teknolojilere Erişim Motivasyon Ölçeği'ni bir ölçme aracı olarak Türk Kültürüne uyarlamak için geçerlik ve güvenirlik çalışmasını gerçekleştirmektir.

Bu amacı gerçekleştirmek için ilk olarak ölçeğe ilişkin dil eşdeğerliği çalışması yürütülmüştür. Dilsel açıdan madde eşdeğerliğinin belirlenmesi noktasında; iki hafta ara ile öğretmenlere uygulanan ölçeğin İngilizce ve Türkçe sürümlerinden elde edilen veriler arasındaki korelasyon katsayısı, bu iki ayrı form arasında yüksek düzeyde, pozitif ve anlamlı bir ilişki olduğunu göstermiştir. Ulaşılan bu sonuç hem ölçek genelinde hem de ölçeğin alt boyutları temelinde eşdeğer olduğuna işaret etmektedir. Sonuç olarak, bu değere göre, uyarlanan ölçeğin Türkçe formunun özgün ölçek ile dilsel geçerliğinin sağlanmıştır.

Uyarlaması gerçekleştirilen "Dijital Teknolojilere Erişim Motivasyon Ölçeği", özgün çalışma olan "Öğretim Üyelerinin Bilgi ve İletişim Teknolojilerine Erişimi Ölçeği'nin" bir alt boyutu olduğu ve özgün ölçeğin geçerlik ve güvenirlik çalışması öğretim üyeleri üzerinde gerçekleştirildiği ve bu uyarlama çalışmasının ise öğretmenler üzerinde yürütüldüğü sebepten ötürü ölçeğin yapı geçerliği çalışması kapsamında öncelikle AFA gerçekleştirilmiştir. AFA sonucuna göre; içsel motivasyon faktörü 4 maddeden $(1,2,3,4)$ oluşmuş ve öz değeri 2,692 olarak ve dışsal motivasyon faktörü ise 4 maddeden $(5,6,7,8)$ oluşmuş ve öz değeri 1,387 olarak bulunmuştur. Bu iki alt faktörün birlikte ilgili motivasyon değişkenine ilişkin varyansın \%50,994'ünü açıkladığı tespit edilmiştir. Bu durum ölçeğin toplam varyans oranının yeterli bir değere sahip olduğunu kanıtlamaktadır. Ayrıca, faktör analizinin ikinci tekrarı sonucunda KMO değeri, .72; Bartlett testinin anlamlılık düzeyi ise 0.000 olarak bulunmuştur. Ölçeğin madde toplam korelasyon değerleri, orta düzeyde $.31-.53$ arasında değişmektedir. Ölçeğin faktör yük değerlerinin ise birinci alt boyutta $.55-.72$ ve ikinci alt boyutta ise $.41-.83$ arasında orta ve yüksek düzeyde ilişkiye sahip olduğu tespit edilmiştir. Sonuç olarak, ölçeğin 2 faktör altında 8 maddenin toplandığı bir yapıya sahip olduğu tespit edilmiştir.

AFA sonucunda elde edilen yeni ölçek yapısının geçerliği, farklı bir çalışma grubundan toplanan veriler üzerinde DFA uygulanarak test edilmiştir. DFA sonucuna göre faktör yük değerleri .42 ile .77 arasında, hata varyans değerleri .41 ile .82 arasında ve tamamı anlamlı düzeydedir. Maddeler ve faktörler arasındaki yol katsayıları içsel motivasyon için .42-.58, dışsal motivasyon için .50-.77 arasındadır. Açıkladığı varyans ve ilişki değerleri orta ve üstü olduğu için bu değerler yeterli kabul edilmiştir. t-değerlerinin tamamı .01 düzeyinde anlamlı ve $\chi 2 / \mathrm{sd}=1.54$ değe $\neg$ rinin kabul edilebilir olduğu tespit edilmiştir. RMSEA $=.061, \mathrm{SRMR}=.055, \mathrm{CFI}=.98, \mathrm{NFI}=.93, \mathrm{NNFI}=.96$ ve $\mathrm{GFI}=.97$ değerlerinin ise kabul edilebilir ve mükemmellik düzeyinde uyum değerleri taşıdığı saptanmıştır. 0.08'den küçük RMSEA ve SRMR değerleri, model ile veri uyumunun güçlü olduğunu göstermektedir. Sonuç olarak, DFA'dan elde edilen bulgular, ölçeğin faktör yapısının kabul edilebilir uyum gösterdiğine işaret etmektedir.

Ölçeğin alt boyutlara ilişkin Cronbach Alpha güvenirlik katsayısı; içsel motivasyon boyutunda .60, dışsal motivasyon boyutunda .71 ve iki alt boyutlu genel yapısında .51'dir. Nunnally (1978)'e göre; madde sayısının 10 ve daha az olması durumunda .50 ve üzerindeki değerler kabul edilebilir olduğu için sonuç olarak, genel olarak ve alt boyutlar bağlamında değerlendirildiğinde ölçeğin hesaplanan güvenirlik katsayıları kabul edilebilir ölçütleri karşıladığı söylenebilir. Ayrıca, içsel motivasyon ve dışsal motivasyon alt boyutlarının maddelerine ilişkin korelasyon katsayısı değerinde pozitif yönlü anlamlı doğrusal bir ilişki tespit edilmiştir. Bu durum, içsel motivasyonu yüksek olan öğretmenlerin dışsal motivasyonun da yüksek olduğuna işaret etmektedir.

Bu bulgular, bu çalışma gruplarından toplanan veriler temelinde Türkçe'ye uyarlanan bu ölçeğin, dijital bölünme dijital teknolojilere erişim motivasyonu konusunun bağımsız olarak veya bir başka konu ile ilişkisi temelinde çözümlenmesi noktasında geçerli bir ölçme gereci olduğunu ortaya koymaktadır. Güvenilirlik sonuçları ise kabul edilebilir düzeydedir. Sonuç olarak, geçerlik ve güvenirliği bu çalışmayla incelenen ölçeğin Türk Kültürüne uyarlanan sürümünün, öğretmenlerin 
dijital teknolojilere erişim motivasyonuna ilişkin algılarını tespit etmek amacıyla kullanılması önerilmektedir.

Bu ölçek, okullarda görevli öğretmenlerin dijital teknolojilere erişim motivasyonuna hakkında yönetimsel ve örgütsel çıkarımlarda bulunabilme noktasında faydalı olabilir. Örneğin, öğretmenlerin dijital teknolojilere erişim motivasyonu düzeyleri düşük çıkan okullarda, okullarda teknoloji kullanımı, teknoloji entegrasyon politikaları, okul iklimi, okul kültürü, yenilikçilik, okulda gerçekleşen bilgi yönetimi, iletişim, vb. konularda çeşitli çıkarımlar yapılabilir. Bu çıkarımlar temelinde okul örgütünün amaçlarının üst düzeyde verimli olarak gerçekleştirilebilmesi adına gerekli tedbirler alınıp politikaları oluşturulabilir. Diğer bir değişle, bu ölçek, okul örgütünün öğretmenlerin dijital teknolojilere erişim motivasyonu durumunu belirlemede bu konuda eğitim yönetimi uğraşılarına katkı sağlayabilir. Ayrıca, bu ölçeğin ölçtüğü özelliklerin başka değişkenlerle ilişkileri ileride yapılacak çalışmalarda ele alınabilir. Son olarak, öğretmenlerin teknolojiye erişeme yönelik erişim motivasyonu, ileride yapılacak çalışmalarda bu ölçek aracılı̆̆ılla toplanacak veriler ve nitel yöntem ile elde edilecek veriler ile detaylı olarak incelenebilir.

\section{Kaynakça}

Akbaşlı, S. ve Durnalı, M. (2017). Halk eğitim merkezlerinde çalışan iş görenlerin yaşam boyu öğrenme anahtar yeterlik algıları. OPUS-Uluslararası Toplum Araştırmaları Dergisi, 7(13), 726-741. DOI: 10.26466/opus.342207

Aksoy, H. H. (2003). Eğitim kurumlarında teknoloji kullanımı ve etkilerine ilişkin bir çözümleme. Eğitim Bilim Toplum Dergisi, 1(4), 4-23.

Akyazı, A. 2007. Bilgi toplumunda dijital bölünme ve yeni medya kavramının dijital bölünmeye etkisi. Yüksek Lisans Tezi. Marmara Üniversitesi, Sosyal Bilimler Enstitüsü, İstanbul.

Atkinson, J., Black, R. ve Curtis, A. (2008). Exploring the digital divide in an Australian regional city: A case study of Albury. Australian Geographer, 39(2), 479- 493.

Bryman, A. ve Cramer, D. (1999). Quantitative Data Analysis with SPSS Release 8 for Windows. London \& New York: Taylor \& Francis.

Büyüköztürk, Ş. (2011). Sosyal Bilimler Iç̧in Veri Analizi El Kitabı. Ankara: PEGEM Akademi Yayınları.

Büyüköztürk, Ş. (2016). Veri analizi el kitabı. Ankara: Pegem Akademi.

Ege, G. B. (2008). Dijital ayrım. Sosyoloji Dergisi, 19, 43-58.

Hu, L. T. ve Bentler, P. M. (1999). Cutoff criteria for fit indexes in covariance structure analysis: Conventional criteria versus new alternatives. Structural Equation Modeling, 6(1), 1-55.

Ilgaz, H. ve Seferoğlu, S. S. (2010). Sayısal uçurumun boyutları ve teknoloji politikaları [Dimensions of the digital divide and technology policies]. In Proceedings of 10th International Educational Technology Conference (IETC-2010) (Vol. 3, pp. 1302-1306).

Kline, R. B. (2011). Principles and practice of structural equation modeling (3nd ed.). New York London: The Guilford.

Norris, P. (2001). Digital divide: Civic engagement information poverty, and the Internet Worldwide. Cambridge: Cambridge University Press.

Nunnally, J.C. (1978). Psychometric theory (2nd ed.). New York: McGraw-Hill.

OECD (Organisation For Economic Cooperation and Development) (2001). Understanding the digital divide. http://www.oecd.org/dataoecd/38/57/1888451.pdf adresinden 12.04.2018 tarihinde erişilmiştir. 
Oruç, E. ve Arslan, S. (2002). Sayısal uçurumun önlenmesi: Stratejik Plan. Telekomünikasyon Kurumu. Sektörel Araştırma ve Stratejiler Dairesi Başkanlığı. http://www.emo.org.tr/ekler/d98edfd003bcd59_ek.pdf?tipi=38\&turu=X\&sube=0 adresinden 21.04.2018 tarihinde erişilmiştir.

Özcivelek, R., Aşkar, M., Geray, H., Tüfekçi, T., Zontul, H. ve Küçükçınar, A. (2000). Sayısal uçurum: Dünya ve Türkiye'de durum. VI. Türkiye'de Internet Konferansı, 9-11.

Prensky, M. (2001). Digital natives, digital immigrants part 1. On the horizon, 9(5), 1-6.

Ritzhaupt, A. D., Liu, F., Dawson, K. ve Barron, A. E. (2013). Differences in student information and communication technology literacy based on socio-economic status, ethnicity, and gender: Evidence of a digital divide in Florida schools. Journal of Research on Technology in Education, 45(4), 291-307.

Seferoğlu, S. S., Avcı, Ü. ve Kalaycı, E. (2008). Sayısal uçurum: Türkiye'deki durum ve mücadelede uygulanabilecek politikalar. 25. Ulusal Bilişim Kurultayı, Bilişim'08 Bildiriler Kitabı (BTIE-2008), 1721, Ankara: Türkiye Bilişim Derneği.

Soomro, K. A., Kale, U., Curtis, R., Akcaoglu, M. ve Bernstein, M. (2018). Development of an instrument to measure Faculty's information and communication technology access (FICTA). Education and Information Technologies, 1-17.

Swain, C. ve Pearson, T. (2001). Bridging the digital divide: A building block for teachers. Learning and Leading with Technology, 28(8), 10-13.

Tavşancıl, E. (2002). Tutumların Ölçülmesi ve SPSS ile Veri Analizi. Ankara: Nobel Akademi.

Tezbaşaran, A. (1997). Likert tipi ölçek hazırlama kılavuzu. Ankara: Türk Psikologlar Derneği.

Tien, F. F. ve Fu, T. T. (2008). The correlates of the digital divide and their impact on college student learning. Computers \& Education, 50(1), 421-436.

Van Dijk, J. A. (2005). The deepening divide: Inequality in the information society. Thousand Oaks: Sage Publications.

Wang, J. ve Wang, X. (2012). Structural equation modeling: Applications using MPLUS: Methods and applications. West Susex: John Wiley \& Sons.

Warschauer, M. (2004). Technology and social inclusion: Rethinking the digital divide. Cambridge: MIT Press. 


\section{Extended Summary}

\section{Introduction}

The "digital divide" phenomenon, which first began to be used to draw attention to inequalities in the context of ownership of information and communication technologies in the United States culture in the mid 1980s (Özcivelek, Aşkar, Geray, Tüfekçi, Zontul and Küçükçınar, 2000) is a complex and multi-dimensional, extending beyond physical access problems (Soomro, Kale, Curtis, Akcaoglu, \& Bernstein, 2018). The "digital divide" is, in particular, the difference in technological access of different national or socio-economic groups (Norris, 2001), the difference in access to social and organizational resources required to use technology effectively (Warschauer, 2004), differences in individual's access to technology (Atkinson, Black \& Curtis, 2008), the differences in individuals' age-related technology use skills -the new generation of 'digital natives' born to the computer and the Internet, and those who use computers and the Internet after a certain age and the 'digital migrants'- (Prensky, 2001). The injustice in organizations and individuals' access to information and communication technologies in different geographical and socio-economic regions is also defined as digital divide (Oruç and Arslan, 2002). This phenomenon can be seen among different groups within a society as well as between different countries (Seferoğlu, Avcı and Kalaycl, 2008). It means a significant difference in access and equity in categorical technology experience, such as income, race, gender, location, or education (Swain \& Pearson, 2001). A similar definition expresses inequality in access to information and communication technologies by individuals according to various variables such as gender, educational status, monthly income, and the geographical area in which they live - especially where economic differences are so pronounced (Ilgaz and Seferoğlu, 2010). The key point in these definitions is the differences in access to digital technology. In addition, information and technical skills are emphasized. Motivation to adopt these technologies is as important as these differences.

Digital divide is also seen in educational organizations (Aksoy, 2003). However, the existing digital divide studies conducted in the field of education have been dealt with in limited ways, most of the studies focusing on students' physical access to information and communication technologies in schools and in homes (Ritzhaupt, Liu, Dawson, \& Barron, 2013). This study focuses on the topic of 'Motivational Access to Digital Technology' motivated by the new digital divide theory (taking into account aspects beyond physical access to information and communication technologies) (Soomro, Kale, Curtis, Akcaoglu, \& Bernstein).

\section{Method}

Firstly, English and Turkish versions of the scale were administered to 40 teachers who are expert in English with a two weeks interval so as to test the language validity of the scale. Pearson Correlation Coefficient was calculated and it ranged from .87-.95 which indicates that Turkish version of the scale has language validity. Secondly, data were collected from 250 volunteer teachers for Exploratory Factor Analysis (EFA) and finally data were collected from 200 volunteer teachers for the Confirmatory Factor Analysis (CFA) in order to determine construct validity of the scale. According to the results of the EFA, as in English version, Turkish version of the scale consisted of two sub-scales. No item was excluded in Turkish version of the scale in which there are 8 items while there are 8 items in the English version. The first subscale (endogenous motivational access) had 4 items and the second subscale (exogenous motivational access) had 4 items. In order to test the structure obtained from the EFA, CFA was administered with different data sets and the factor structure was determined to be acceptable. The results of the CFA indicated that model fit indices of the scale proved a good fit (Chi Square $=1.54$; RMSEA $=.061$, SRMR=.055, $\mathrm{CFI}=.98, \mathrm{NFI}=.93, \mathrm{NNFI}=.96, \mathrm{GFI}=.97)$. 
Reliability of the scale was determined through Cronbach's Alpha Coefficient which was .51 for the overall of the scale. It was .60 for the endogenous motivational access subscale and .71 for the exogenous motivational access subscale. In addition, the relationships between the subscales and scale was determined through Pearson Correlation Coefficient. The value indicated that there are statistically significant and positive relationships between subscales and scale. It proves that the subscales have a consistency.

\section{Conclusion}

In conclusion, the aim of this study is to adapt 'Motivational Access' sub-dimension of Faculty's Information and Communication Technology Access (FICTA) (Soomro, Kale, Curtis, Akcaolu \& Bernstein, 2018) into Turkish as independent measurement instrument. The findings of the study indicated that 'Motivational Access to Digital Technologies Sub-dimension' is a valid, reliable and independent measurement tool when adapted into Turkish and administered to teachers. Turkish version of the scale has the same two sub-dimensions and same items as in original scale which are endogenous motivational access and exogenous motivational access. Furthermore, the adapted version of the scale can be used to determine the perceptions of teachers working in educational organizations regarding motivational access to digital technologies. In addition, this scale can be used in educational organizations to analyze the relationship between different appropriate topics and topics related to the purpose of the adapted scale. Also, the studies which uses the scale can be supported by qualitative techniques. 